\title{
Effectiveness of Ivabradine Treatment in Different Subpopulations with Stable Angina in Clinical Practice: A Pooled Analysis of Observational Studies
}

\author{
Karl Werdan ${ }^{a}$ Stefan Perings ${ }^{b}$ Ralf Köster ${ }^{d}$ Malte Kelm ${ }^{c}$ Thomas Meinertz ${ }^{\mathrm{e}}$ \\ Georg Stöckl ${ }^{f}$ Ursula Müller-Werdan ${ }^{g, h}$ \\ ${ }^{a}$ Department of Medicine and Heart Centre, University Hospital of the Martin Luther University of Halle-Wittenberg, \\ Halle (Saale), ${ }^{b}$ CardioCentrum, and ${ }^{c}$ Department of Cardiology, Pneumology and Angiology, Düsseldorf \\ University Hospital, Düsseldorf, d Department of Cardiology and Angiology, Johanniter Hospital, Geesthacht, \\ eDepartment of Cardiology and Angiology, University Heart Center, Hamburg, ${ }^{\mathrm{f}}$ Department of Medical Affairs, \\ Servier Deutschland GmbH, Munich, ${ }^{9}$ Department of Geriatrics, Evangelisches Geriatriezentrum, and \\ ${ }^{\mathrm{h}}$ Chair of Geriatrics, Charité - Universitätsmedizin Berlin, Berlin, Germany
}

\section{Key Words}

Stable angina pectoris - Subpopulation $\cdot$ Heart rate . Ivabradine · Pooled analysis · Clinical practice .

Observational studies

\begin{abstract}
Objectives: The efficacy of ivabradine has been demonstrated in different subpopulations of stable angina patients in randomized clinical trials. This study explored its effectiveness in subpopulations seen in clinical practice as they often differ from those of randomized trials. Methods: Data were pooled from three German observational studies with similar inclusion criteria (stable angina and heart rate $\geq 60 \mathrm{bpm}$ ). All patients received $2.5,5$, or $7.5 \mathrm{mg}$ b.i.d. of ivabradine for 4 months, with or without concomitant beta-blocker. Antianginal effectiveness was analyzed in subpopulations defined by gender, age, heart rate, angina severity, use of concomitant beta-blocker, previous percutaneous coronary intervention procedure, and comorbidities (including previous myocardial infarction and diabetes). Results: Treatment data
\end{abstract}

were available on 8,555 patients, where therapy with ivabradine was associated with a significant reduction in the frequency of angina attacks and consumption of short-acting nitrates of $87 \%$. Effectiveness was maintained in all investigated subpopulations, with a reduction in antianginal parameters of $82-90 \%$. Clinical status (Canadian Cardiovascular Society class) and quality of life were also improved. Ivabradine was well tolerated in all subgroups. Conclusions: Ivabradine is effective and safe in all subpopulations of angina patients seen in clinical practice, independent of age, comorbidities, and use of beta-blocker.

$$
\begin{aligned}
& \text { (C) } 2016 \text { The Author(s) } \\
& \text { Published by S. Karger AG, Basel }
\end{aligned}
$$

\section{Introduction}

Uncontrolled heart rate can induce or worsen myocardial ischemia and angina symptoms by disrupting myocardial oxygen balance $[1,2]$. Elevated heart rate increases the demand of myocardial oxygen and at the same time limits oxygen supply to the heart by reducing

\section{KARGER}

E-Mail karger@karger.com www.karger.com/crd

\section{C) 2016 The Author(s) \\ Published by S. Karger AG, Basel 0008-6312/16/1353-0141\$39.50/0}

This article is licensed under the Creative Commons AttributionNonCommercial-NoDerivatives 4.0 International License (CC BYNC-ND) (http://www.karger.com/Services/OpenAccessLicense) Usage and distribution for commercial purposes as well as any distribution of modified material requires written permission.
Prof. Karl Werdan

Department of Medicine and Heart Centre

Martin Luther University of Halle-Wittenberg, Ernst-Grube-Strasse 40

DE-06120 Halle (Saale) (Germany)

E-Mail karl.werdan@medizin.uni-halle.de 
the time for diastolic perfusion. Both mechanisms contribute to myocardial ischemia, making heart rate reduction an obvious strategy to prevent oxygen imbalance and improve angina symptoms [3]. Such a strategy can be achieved by using a beta-blocker, which is a well-established treatment to control the heart rate and symptoms in stable angina patients [4]. However, besides their effects on heart rate, beta-blockers have additional properties that can negatively affect cardiac function [3]. Ivabradine, an inhibitor of the $I_{\mathrm{f}}$ pacemaker current, selectively targets the heart rate and, in contrast to beta-blockers, does not reduce myocardial contractility or relaxation [5]. The mechanisms of anti-ischemic and antianginal efficacy of ivabradine were first elucidated in experimental studies [5] and confirmed in recent clinical trials. This includes an increase in myocardial diastolic perfusion time [6], enhancement in coronary flow reserve [7], improvement in endothelial function [8], and enhancement in coronary collateral flow in patients with chronic stable coronary artery disease [9]. This makes ivabradine an important antianginal and anti-ischemic therapeutic strategy.

The anti-ischemic effect of ivabradine had been demonstrated in a range of randomized clinical trials (RCTs) [10-14], supporting its use for the treatment of symptoms in patients with stable angina alone or in combination with a beta-blocker [15]. Moreover, the antianginal efficacy of ivabradine has been established across a variety of subpopulations with diverse comorbidities, as demonstrated by a pooled analysis of five RCTs [16]. However, patients seen in clinical practice often differ from those included in RCTs and may not respond similarly to treatment. The stringent inclusion/exclusion criteria used in RCTs, with the frequent exclusion of elderly patients and patients with comorbidities, usually lead to populations with a lower risk profile compared with real-world settings [17]. Therefore, the question of the effect of ivabradine in patients with stable angina seen in everyday routine practice has been addressed in a range of observational studies, which confirmed both the effectiveness and safety of the drug when assessed in real-life situations [18-20]. The question remains whether this beneficial effect observed in real clinical practice in a broad population still applies to subpopulations with specific characteristics.

The aim of the study described here was to assess the effectiveness and safety of ivabradine in different subpopulations of stable angina patients in clinical practice. This was achieved by pooling the data from three available observational trials: ADDITIONS (Practical Daily Efficacy and Safety of Procoralan ${ }^{\circledR}$ in Combination with BetaBlockers) [18], REDUCTION (Reduction of Ischemic Events by Reduction of Heart Rate in the Treatment of Stable Angina with Ivabradine) [19], and RESPONSIfVE (Evaluation of Effectiveness and Therapeutic Response to Ivabradine in Daily Practical Use for Chronic Stable Angina Patients) [20], which led to a population large enough for meaningful subgroup analysis.

\section{Patients and Methods}

\section{Participants and Study Design}

Data were pooled from three German observational studies: ADDITIONS [18], REDUCTION [19], and RESPONSIfVE [20] (table 1). These were multicenter, open-label, prospective studies including patients with stable angina pectoris in $818,1,503$, and 338 centers in Germany, respectively. The studies were chosen for analysis as they are the only published and large-scale (each $>1,000$ patients) German observational cohorts for ivabradine use in its angina indication. These cohorts show very similar inclusion and evaluation criteria with detailed documentation and follow-up of patients. This provides a representative picture of treatment practice with ivabradine in Germany from three studies with relatively low heterogeneity. All investigators (general practitioners, internal medicine physicians, or cardiologists in private practice) filled out a standardized clinical questionnaire during the patient's treatment that included the following information: medical history and concomitant medication, heart rate, Canadian Cardiovascular Society (CCS) classification, number of angina attacks, consumption of short-acting nitrates, and quality of life using the EQ-5D index and EQ VAS (visual analog scale) scores. Patients were only eligible for inclusion if they had given their written informed consent. For 47 patients in the REDUCTION study, questionnaires were filled out at the end of the study rather than on an ongoing basis, and those patients were excluded from the original trial report [19]. However, these data can still be considered as valid, and these 47 patients (including $24 \mathrm{pa}-$ tients with available effectiveness data) were included in the present pooled effectiveness and safety analysis. All patients in the RESPONSIfVE trial were included in the pooled analysis, whereas three patients in the ADDITIONS trial with unclear betablocker therapy were excluded. All three studies were conducted in accordance with the Declaration of Helsinki and complied with the ethical guidelines of the European Independent Ethics Committee.

The three studies had similar inclusion criteria: patients with a resting heart rate $\geq 60 \mathrm{bpm}$ and in need of symptomatic treatment for stable angina pectoris. The main difference related to the use of beta-blocker therapy: concomitant treatment with beta-blocker was part of the inclusion criteria for the ADDITIONS trial [18], while it was optional for both the REDUCTION and RESPONSIfVE trials $[19,20]$ (table 1).

The study design was similar in all studies, with three scheduled visits: the first visit performed at baseline and the following two visits after approximately 1 and 4 months of treatment. After the baseline visit, therapy was started with ivabradine $5 \mathrm{mg}$ b.i.d. and could be increased to $7.5 \mathrm{mg}$ b.i.d. after 2-4 weeks. A lower 
Table 1. Study design and main effectiveness results of the ADDITIONS, REDUCTION, and RESPONSIfVE trials [18-20]

\begin{tabular}{|c|c|c|c|}
\hline \multicolumn{4}{|l|}{ Design } \\
\hline Type of study & $\begin{array}{l}\text { Observational, prospective, } \\
\text { in addition to beta-blocker }\end{array}$ & $\begin{array}{l}\text { Observational, prospective, } \\
\text { with contraindication or } \\
\text { intolerance to beta-blocker }\end{array}$ & $\begin{array}{l}\text { Observational, prospective, } \\
\text { with or without beta-blocker }\end{array}$ \\
\hline Patients, $\mathrm{n}$ & 2,330 & 4,954 & 1,250 \\
\hline \multicolumn{4}{|l|}{ Main effectiveness results } \\
\hline Resting heart rate, bpm & -19.4 & -12.4 & -15.4 \\
\hline Angina attacks/week, n & -1.4 & -2.0 & -1.1 \\
\hline Use of short-acting nitrates/week, $\mathrm{n}$ & -1.9 & -2.8 & -1.4 \\
\hline CCS classification, $\%$ of patients & & n.a. & \\
\hline Class I & Increased from 29 to $68 \%$ & & Increased from 24 to $66 \%$ \\
\hline
\end{tabular}

Main effectiveness results are shown as mean change from baseline after 4 months of ivabradine treatment except for CCS classification. n.a. = Not available.

dose of $2.5 \mathrm{mg}$ b.i.d. could be considered in patients with severe renal dysfunction (creatinine clearance $<15 \mathrm{ml} / \mathrm{min}$ ) or a low resting heart rate $(<50 \mathrm{bpm})$ during treatment, or in the elderly $(\geq 75$ years). Follow-up lasted 4 months. Further details of the study designs can be found in the respective publications of the trials [18-20].

\section{Definition of Subpopulations}

The pooled data were analyzed in different subpopulations of interest defined according to the following baseline criteria: gender, age ( $\geq 75$ years), heart rate $(\geq 70 \mathrm{bpm})$, angina severity (CCS classification), concomitant medication (any beta-blockers or metoprolol), previous percutaneous coronary intervention (PCI), or comorbidities: previous myocardial infarction (MI), diabetes, asthma/chronic obstructive pulmonary disease (COPD), and renal dysfunction. The effectiveness of ivabradine was also assessed in patients with concomitant metoprolol and heart rate $\geq 70 \mathrm{bpm}$, closely reflecting the practical application of ivabradine in combination with the most commonly used beta-blocker in the analyzed studies.

\section{Measured Parameters and Statistical Methods}

The following parameters were evaluated for effectiveness in the pooled data set: resting heart rate (determined after at least 5 min at rest by manual assessment or ECG recording), number of angina attacks, use of short-acting nitrates, and CCS classification. Quality of life data (EQ-5D index and EQ VAS scores) were only available for the ADDITIONS trial. Absolute and relative changes from baseline were analyzed by a one-sample $t$ test. Changes in CCS classification were analyzed by the signed-rank test. Safety was assessed by analyzing the frequency of adverse events, which were coded with MedDRA version 17.1. All analyses were performed in a descriptive manner using SAS software (version 9.3), without any formal testing of predefined statistical hypotheses.

Antianginal Effectiveness of Ivabradine in Clinical Practice

\section{Results}

\section{Characteristics of the Pooled Population}

The pooled population used for effectiveness analysis comprised a total of 8,555 patients with available data: 2,327 patients from the ADDITIONS trial, 4,978 patients from the REDUCTION trial, and 1,250 patients from the RESPONSIfVE trial.

The baseline characteristics of the pooled population are presented in table 2: mean age was 65.4 years, $41 \%$ were female, and $19 \%$ were $\geq 75$ years. Half of the population had undergone PCI (49\%), and about two fifths (41\%) had a history of MI. Hypertension and dyslipidemia were present in the vast majority of patients (91 and $80 \%$, respectively). Diabetes (46\%) and asthma/COPD (35\%) were frequent, while renal dysfunction was less common (6\%). Patients had a mean heart rate of $83.3 \mathrm{bpm}$ at baseline and experienced a mean of 2.1 angina attacks per week. The distribution of CCS classification was $27 \%$ for class I, $53 \%$ for class II, and $20 \%$ for class III + IV.

Concerning angina related-treatments, $40 \%$ of patients were receiving a beta-blocker at baseline (predominantly metoprolol: $16 \%$ ), 19\% a calcium antagonist, and $18 \%$ a long-acting nitrate. Other concomitant medications were typical of those used in cardiovascular patients: aspirin (77\%), statins (64\%), and angiotensinconverting enzyme inhibitors (49\%).

Concerning quality of life parameters, aged patients ( $\geq 75$ years) had a lower quality of life at baseline com- 
Table 2. Baseline characteristics in the pooled data set

\begin{tabular}{|c|c|}
\hline Characteristic (number of patients with data) & $\begin{array}{l}\text { Pooled } \\
\text { population }\end{array}$ \\
\hline \multicolumn{2}{|l|}{ Demographic characteristics } \\
\hline Age $(n=8,525)$, years & $65.4 \pm 10.58$ \\
\hline$\geq 75$ years $(n=8,525)$ & $1,644(19)$ \\
\hline Female sex $(n=8,198)$ & $3,347(41)$ \\
\hline Height $(\mathrm{n}=8,329), \mathrm{cm}$ & $170.8 \pm 8.37$ \\
\hline Weight $(\mathrm{n}=8,320), \mathrm{kg}$ & $81.4 \pm 14.30$ \\
\hline \multicolumn{2}{|l|}{ Medical history } \\
\hline Previous MI $(\mathrm{n}=8,363)$ & $3,405(41)$ \\
\hline Previous PCI $(\mathrm{n}=8,387)$ & $4,073(49)$ \\
\hline Hypertension $(\mathrm{n}=7,763)$ & $7,091(91)$ \\
\hline Dyslipidemia $(\mathrm{n}=7,655)$ & $6,124(80)$ \\
\hline Diabetes mellitus $(n=5,757)$ & $2,619(46)$ \\
\hline Asthma/COPD $(\mathrm{n}=8,555)$ & $2,975(35)$ \\
\hline Renal dysfunction $(\mathrm{n}=8,555)$ & $483(6)$ \\
\hline \multicolumn{2}{|l|}{ Clinical findings } \\
\hline Heart rate $(\mathrm{n}=8,511), \mathrm{bpm}$ & $83.3 \pm 14.13$ \\
\hline Number of angina attacks/week $(n=8,207)$ & $2.1 \pm 2.79$ \\
\hline Use of short-acting nitrates/week $(n=7,593)$ & $2.8 \pm 3.95$ \\
\hline \multicolumn{2}{|l|}{ Quality of life $\mathrm{e}^{\mathrm{a}}$} \\
\hline EQ-5D index $(n=2,257)$ & $0.66 \pm 0.27$ \\
\hline EQ VAS scores $(n=2,170)$ & $57.4 \pm 18.30$ \\
\hline \multicolumn{2}{|l|}{ CCS classification $(\mathrm{n}=8,091)$} \\
\hline Class I & $2,163(27)$ \\
\hline Class II & $4,264(53)$ \\
\hline Class III & $1,600(20)$ \\
\hline Class IV & $64(<1)$ \\
\hline \multicolumn{2}{|l|}{ Medication } \\
\hline Beta-blockers $(\mathrm{n}=8,539)$ & $3,413(40)$ \\
\hline Metoprolol $(\mathrm{n}=8,555)$ & $1,376(16)$ \\
\hline ACE inhibitors $(\mathrm{n}=8,555)$ & $4,205(49)$ \\
\hline Calcium antagonists $(\mathrm{n}=8,555)$ & $1,597(19)$ \\
\hline Long-acting nitrates $(\mathrm{n}=8,555)$ & $1,518(18)$ \\
\hline Molsidomine $(\mathrm{n}=8,555)$ & $1,102(13)$ \\
\hline Aspirin $(\mathrm{n}=8,555)$ & $6,569(77)$ \\
\hline Statins $(\mathrm{n}=8,555)$ & $5,473(64)$ \\
\hline
\end{tabular}

Values are means \pm SD or $\mathrm{n}(\%)$ of patients. ACE $=$ Angiotensin-converting enzyme.

${ }^{a}$ Quality of life was only available for the ADDITIONS trial.

pared with younger patients (EQ-5D: $0.57 \pm 0.28$ for $\geq 75$ years vs. $0.68 \pm 0.26$ for $<75$ years; EQ VAS score: $52.8 \pm$ 17.5028 for $\geq 75$ years vs. $58.5 \pm 18.34$ for $<75$ years).

\section{Effect of Ivabradine on Heart Rate}

Heart rate was reduced from $83.3 \pm 14.13 \mathrm{bpm}$ at baseline to $72.7 \pm 10.48 \mathrm{bpm}$ after 1 month (12\% relative reduction) and to $68.6 \pm 9.07 \mathrm{bpm}$ after 4 months of ivabradine treatment (16\% relative reduction). Overall, $85 \%$ of patients had achieved a heart rate $<70 \mathrm{bpm}$ or a reduc- tion in heart rate of $\geq 10 \mathrm{bpm}$ after 4 months of treatment (58\% with heart rate $<70 \mathrm{bpm}$ and $69 \%$ with heart rate reduction of $\geq 10 \mathrm{bpm}$ ).

\section{Antianginal Effectiveness of Ivabradine}

In the overall population, treatment with ivabradine was associated with a progressive reduction in the mean number of angina attacks per week (from $2.1 \pm 2.79$ at baseline to $0.7 \pm 1.86$ and $0.3 \pm 1.25$ at 1 and 4 months, respectively; fig. 1a). A similar decrease was observed for use of short-acting nitrates per week (from $2.8 \pm 3.95$ at baseline to $1.0 \pm 2.12$ and $0.4 \pm 1.40$ at 1 and 4 months, respectively; fig. 1b). Treatment with ivabradine was also associated with a significant improvement in the clinical status of the overall population assessed by the distribution of CCS class (fig. 1c). The majority of patients shifted to class I at the end of the study treatment (from $27 \%$ at baseline to $67 \%$ at 4 months), while the proportion of patients in the more severe classes was substantially reduced (class II: from $53 \%$ at baseline to $29 \%$ at 4 months; class III + IV: from $20 \%$ at baseline to $4 \%$ at 4 months).

A similar pattern in antianginal effectiveness was observed in patients receiving concomitant metoprolol at baseline (fig. 2). In that subset of patients, the mean number of angina attacks progressively decreased from $1.6 \pm$ 2.20 at baseline to $0.5 \pm 1.20$ and $0.3 \pm 0.91$ at 1 and 4 months, respectively. Use of short-acting nitrates was reduced from $2.2 \pm 3.26$ at baseline to $0.7 \pm 1.43$ and $0.3 \pm$ 1.08 at 1 and 4 months, respectively. Finally, an improvement in CCS class distribution was noted at the end of the study, with the majority of patients (64\%) graded as class I at the last visit (baseline: $26 \%$ ) and fewer patients as class II (32\%) and III + IV (4\%; versus 51 and $22 \%$, respectively, at baseline). The effects of ivabradine on angina attacks, nitrate use, and CCS reclassification were comparable for other concomitantly used cardioselective betablockers (bisoprolol, carvedilol, and nebivolol).

The antianginal effectiveness of ivabradine in various subpopulations of interest defined by demographic characteristics, heart rate at baseline, angina severity, comorbidities, and concomitant medication, is presented in figure 3. The relative reduction in the number of angina attacks per week at 4 months was consistent among all investigated subgroups, ranging from 82 to $90 \%$, and was comparable to that seen in the overall population (87\%). Similar findings were observed for use of short-acting nitrates, with a consistent relative reduction in all subgroups (from 82 to $90 \%$ ), in line with the overall reduction of $87 \%$ in the pooled population. 
Fig. 1. Antianginal effectiveness of ivabradine in the overall population. a Number of angina attacks/week. b Use of short-acting nitrates/week. c Distribution of CCS class. Bars are means \pm SD. ${ }^{*} \mathrm{p}<0.0001$ for changes from baseline or CCS class changes.
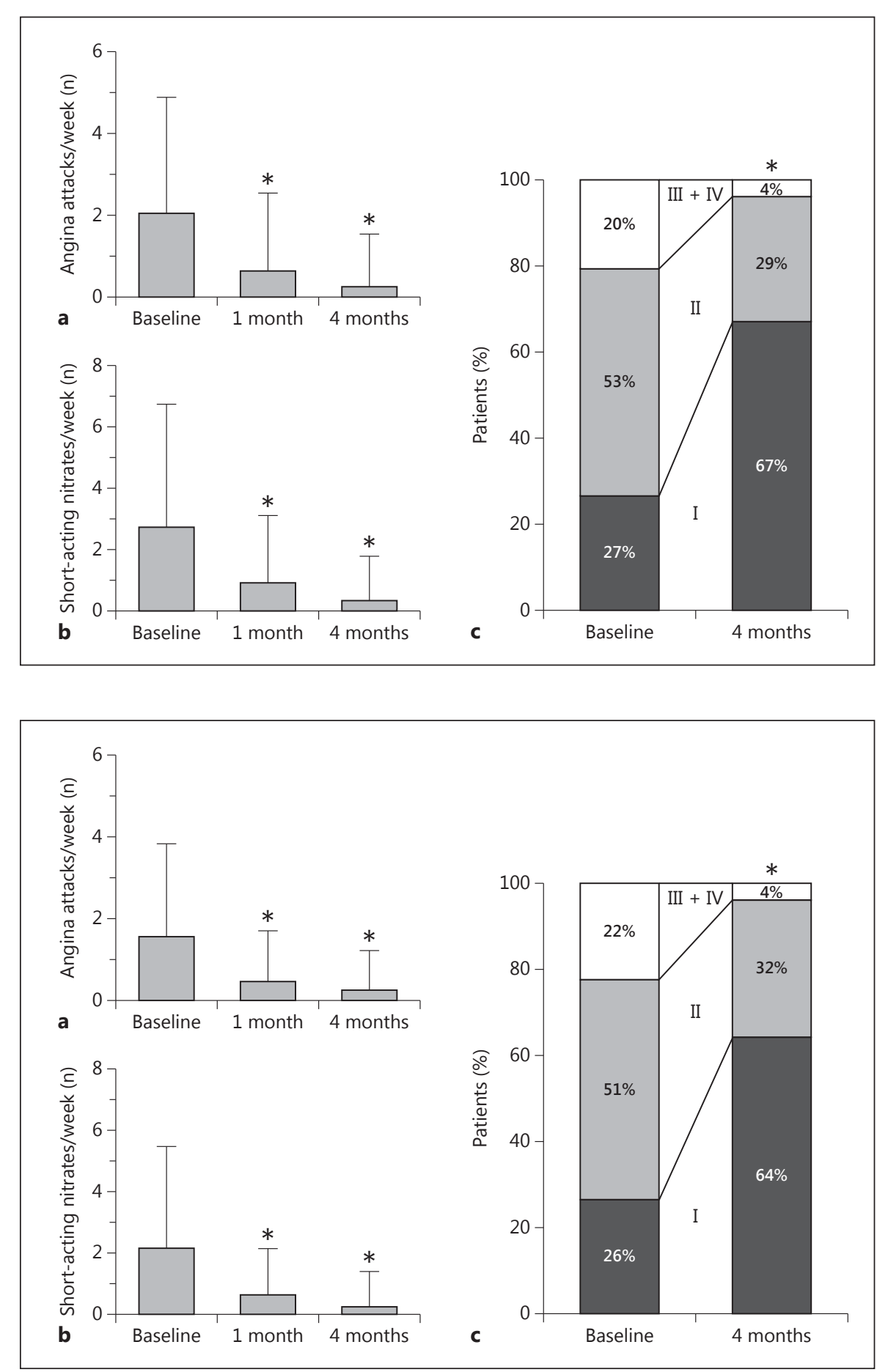

Fig. 2. Antianginal effectiveness of ivabradine in patients with concomitant metoprolol at baseline. a Number of angina attacks/ week. b Use of short-acting nitrates/week. c Distribution of CCS class. Bars are means \pm SD. ${ }^{*} \mathrm{p}<0.0001$ for changes from baseline or CCS class changes.
Quality of life data at 4 months, assessed by the EQ-5D index and VAS scores, are presented in table 3 for the overall ADDITIONS population and subgroups of interest. As previously shown, ivabradine significantly improved quality of life parameters in the whole population as well as in patients with previous PCI and with concomitant metoprolol medication [18, 21, 22]. Here, we extend the findings to a larger range of patient subgroups, where ivabradine showed consistent improvement in quality of life, using both measurement systems, in all 


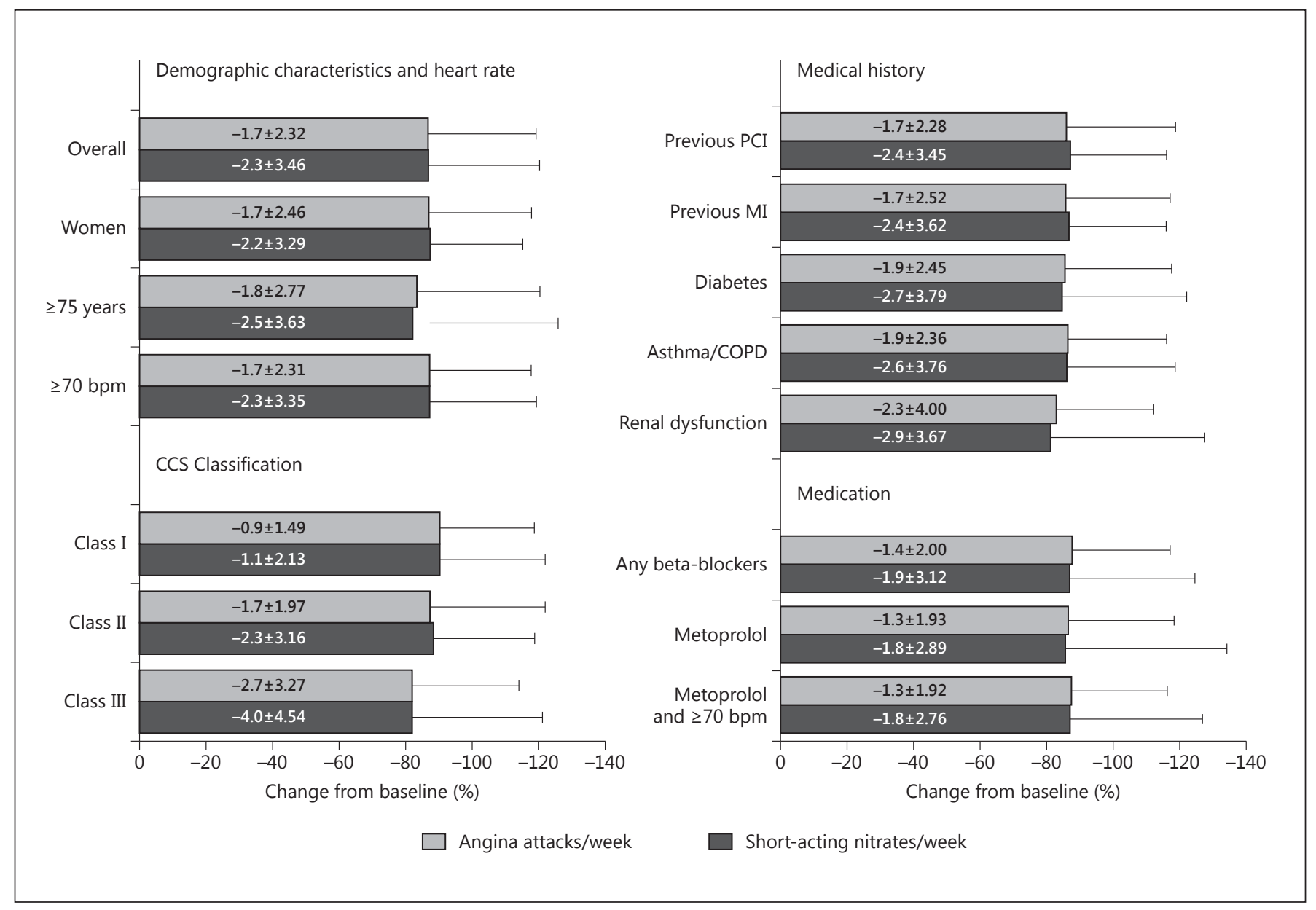

Fig. 3. Antianginal effectiveness after 4 months of treatment with ivabradine in different subpopulations. Bars are relative changes from baseline (means $\pm \mathrm{SD}$ ). Values shown in bars are absolute changes from baseline (means $\pm \mathrm{SD}) . \mathrm{p}<0.0001$ for all changes.

considered subgroups (absolute changes from baseline ranging from $0.11 \pm 0.18$ to $0.26 \pm 0.28$ for EQ-5D index and from $6.3 \pm 9.60$ to $16.2 \pm 16.94$ for EQ VAS score; $\mathrm{p}<0.0001$ for all changes).

Beta-blocker treatment was stopped in $1 \%(\mathrm{n}=79)$ and initiated in $0.4 \%(\mathrm{n}=36)$ of patients in the total cohort during the study period. Ivabradine was discontinued in $4 \%(\mathrm{n}=361)$ of patients.

\section{Safety and Tolerability}

The pooled population considered for analysis of safety included a total of 8,578 patients: 2,327 patients for the ADDITIONS trial, 5,001 patients for the REDUCTION trial, and 1,250 patients for the RESPONSIfVE trial.

Overall, adverse drug reactions were rare (1.2\% of patients, $\mathrm{n}=99)$ and mainly not serious. Nausea $(0.2 \%, \mathrm{n}=$
$15)$, dizziness $(0.2 \%, \mathrm{n}=14)$, photopsia $(0.2 \%, \mathrm{n}=13)$, and bradycardia $(0.1 \%, \mathrm{n}=9)$ were the most reported reactions. The frequency and type of adverse drug reactions were similar in the overall population and in all analyzed subgroups, including in older ( $\geq 75$ years) versus younger ( $<75$ years) patients ( 1.5 vs. $1.1 \%$, respectively).

\section{Discussion}

This pooled analysis shows that the antianginal effectiveness of ivabradine is similar across a large range of subpopulations of stable angina patients seen in realworld clinical practice. Our results indicate that ivabradine is associated with a sustained and significant reduction in angina attacks and consumption of short-act- 
Table 3. Quality of life after 4 months of treatment with ivabradine in different subpopulations

\begin{tabular}{|c|c|c|c|c|c|c|}
\hline & \multicolumn{3}{|c|}{ EQ-5D index } & \multicolumn{3}{|c|}{ EQ VAS score } \\
\hline & $\mathrm{n}$ & baseline & $\begin{array}{l}\text { change from } \\
\text { baseline* }\end{array}$ & $\mathrm{n}$ & baseline & $\begin{array}{l}\text { change from } \\
\text { baseline* }\end{array}$ \\
\hline Overall & 2,171 & $0.66 \pm 0.27$ & $0.17 \pm 0.23$ & 2,037 & $57.4 \pm 18.30$ & $15.4 \pm 15.55$ \\
\hline \multicolumn{7}{|c|}{ Demographic characteristics and heart rate } \\
\hline Women & 872 & $0.62 \pm 0.28$ & $0.18 \pm 0.24$ & 824 & $55.2 \pm 18.21$ & $15.9 \pm 15.65$ \\
\hline$\geq 75$ years & 442 & $0.57 \pm 0.28$ & $0.17 \pm 0.26$ & 419 & $52.8 \pm 17.50$ & $14.7 \pm 15.24$ \\
\hline$\geq 70 \mathrm{bpm}$ & 1,995 & $0.66 \pm 0.26$ & $0.17 \pm 0.23$ & 1,870 & $57.2 \pm 18.23$ & $15.7 \pm 15.54$ \\
\hline \multicolumn{7}{|l|}{ CCS classification } \\
\hline Class I & 578 & $0.77 \pm 0.22$ & $0.11 \pm 0.18$ & 565 & $65.3 \pm 17.37$ & $6.3 \pm 9.60$ \\
\hline Class II & 989 & $0.66 \pm 0.23$ & $0.17 \pm 0.21$ & 972 & $57.1 \pm 16.81$ & $8.6 \pm 10.87$ \\
\hline Class III & 379 & $0.49 \pm 0.29$ & $0.26 \pm 0.28$ & 375 & $46.1 \pm 15.63$ & $11.5 \pm 11.60$ \\
\hline \multicolumn{7}{|l|}{ Medical history } \\
\hline Previous PCI & 1,044 & $0.67 \pm 0.26$ & $0.15 \pm 0.22$ & 981 & $58.7 \pm 18.50$ & $14.2 \pm 14.97$ \\
\hline Previous MI & 1,371 & $0.67 \pm 0.26$ & $0.16 \pm 0.22$ & 1,284 & $58.5 \pm 18.30$ & $15.1 \pm 15.54$ \\
\hline Diabetes & 726 & $0.60 \pm 0.29$ & $0.19 \pm 0.25$ & 687 & $54.4 \pm 18.12$ & $15.9 \pm 16.15$ \\
\hline Asthma/COPD & 419 & $0.58 \pm 0.31$ & $0.18 \pm 0.27$ & 392 & $53.6 \pm 18.07$ & $15.8 \pm 16.15$ \\
\hline Renal dysfunction & 162 & $0.51 \pm 0.31$ & $0.21 \pm 0.30$ & 150 & $48.4 \pm 16.93$ & $16.2 \pm 16.94$ \\
\hline \multicolumn{7}{|l|}{ Medication } \\
\hline Any beta-blockers & 2,145 & $0.66 \pm 0.27$ & $0.17 \pm 0.23$ & 2,012 & $57.4 \pm 18.27$ & $15.3 \pm 15.55$ \\
\hline Metoprolol & 905 & $0.67 \pm 0.27$ & $0.16 \pm 0.23$ & 859 & $57.7 \pm 18.25$ & $14.7 \pm 15.49$ \\
\hline Metoprolol and $\geq 70 \mathrm{bpm}$ & 828 & $0.68 \pm 0.26$ & $0.16 \pm 0.22$ & 784 & $57.5 \pm 18.24$ & $15.2 \pm 15.43$ \\
\hline
\end{tabular}

Values are means \pm SD. ${ }^{*} \mathrm{p}<0.0001$ for all changes from baseline.

ing nitrates, and an improvement in CCS class (reflecting exercise tolerance) and quality of life. These results were consistent in all analyzed subgroups, including women, the elderly, patients with a history of PCI or MI, and patients on beta-blockers. In addition, the drug had a good safety and tolerability profile in all considered subgroups.

Compared with pooled randomized trials with ivabradine [16], the patients in our study were older $(\geq 75$ years: 19 vs. $4 \%$ ) and more often women (41 vs. $18 \%$ ). They also presented with a higher heart rate at baseline (83.3 vs. $73.0 \mathrm{bpm}$ ) and more hypertension (91 vs. 59\%), dyslipidemia ( 80 vs. $53 \%$ ), diabetes ( 46 vs. $19 \%$ ), and asth$\mathrm{ma} / \mathrm{COPD}$ (35 vs. $6 \%$ ). Thus, this pooled analysis complements and extends the demonstration of efficacy and safety of ivabradine in a broader population from that seen in randomized trials [10-14].

Among the subpopulations analyzed, the elderly deserve attention as they represent a growing population of stable angina patients with specific characteristics. Elderly patients are often underrepresented in RCTs [23], and diagnosis of coronary artery disease can be difficult as they can present with atypical symptoms [4]. Aged patients remain challenging to treat because of a higher prevalence of comorbidities and more frequent side effects or intolerance to drugs [24]. Reduction in angina attacks and consumption of short-acting nitrates has been previously shown in a subgroup of 91 elderly patients with stable angina in a pooled analysis of RCTs [16]. Here, we demonstrated the antianginal effectiveness of ivabradine in a sizeable population of more than 1,600 patients $\geq 75$ years seen in real clinical practice. In addition to the reduction in angina attacks (by $84 \%$ ) and use of short-acting nitrates (by $82 \%$ ), ivabradine significantly improved the quality of life in this aged population with impaired health status scores at baseline. Importantly, all these beneficial effects were accompanied by a good safety profile, as ivabradine displayed a similar rate of adverse events compared with younger patients.

Nearly half (46\%) of our population had diabetes. Regular physical activity is an important part of the management of diabetes, and this may be impaired by angina [25]. Recent trial data indicate that $82 \%$ of patients with coronary artery disease and type 2 diabetes may have angina-related symptoms despite the use of recommended therapies [26]. The need for therapies that effectively reduce symptoms is thus essential. Here, we demonstrated 
a significant decrease in the number of angina attacks (by $86 \%$ ) and use of short-acting nitrates (by $85 \%$ ) with ivabradine in angina patients with diabetes. Our data are consistent with the improvement in exercise tolerance and the reduction in angina symptoms observed in RCTs with ivabradine in subgroups of patients with angina and diabetes [16, 27]. Diabetic patients often develop cardiac autonomic neuropathy, leading to elevated sympathetic tone and resting tachycardia [28]. Accordingly, in a recent survey, the resting heart rate of stable coronary artery disease patients with diabetes was $5 \mathrm{bpm}$ higher than those without diabetes [29]. As a result, a large proportion of angina patients who have diabetes may be eligible for ivabradine treatment. Another important point to consider is the potential detrimental effects of antianginal therapies, such as beta-blockers and calcium channel blockers, on the glycemic control of diabetic patients [25]. Importantly, ivabradine does not alter glycosylated hemoglobin $\mathrm{HbA}_{1 \mathrm{c}}$ and fasting glucose, whereas atenolol and amlodipine increase levels of both parameters [27]. Our results suggest that ivabradine is a safe and efficient treatment for angina patients with diabetes.

One fifth of patients report symptoms of angina 1 year after an event of acute MI [30]. Moreover, two fifths of patients with stable angina remain symptomatic despite revascularization [31]. In this study, patients with previous MI and PCI accounted for $41 \%(\mathrm{n}=3,405)$ and $49 \%$ $(\mathrm{n}=4,073)$ of the pooled population, respectively. Ivabradine decreased angina symptoms to the same extent in both subpopulations (angina attacks reduced by $86 \%$ and use of short-acting nitrates by $87 \%$ ), consistent with the results of RCTs [16]. Of note, a recent report indicates that ivabradine can limit episodes of stunning in patients with coronary artery disease [32]. This cardioprotective effect, together with the anti-ischemic properties of ivabradine, could play a significant role in limiting the progression to myocardial hibernation and left ventricular dysfunction commonly observed in patients with a history of MI [33]. In addition, ivabradine was recently shown to improve endothelial function in coronary artery disease patients after PCI [8]. In many patients with ischemic heart disease, microvascular dysfunction is increasingly becoming recognized as an important mechanism of angina, in addition to the more classic obstructive atherosclerosis mechanism [34]. Microvascular dysfunction is particularly prominent in patients with recurrent angina after PCI [35]. By improving endothelial function, ivabradine may contribute to maintaining coronary dilation, hence preventing microvascular dysfunction and the recurrence of angina attacks after coronary intervention.
In addition to the pain and discomfort, angina symptoms impair the quality of life of patients by limiting their ordinary physical activities and altering their psychological well-being. Patients with angina may further reduce their daily activities to prevent the occurrence of angina attacks, thereby contributing to the degradation of their quality of life. Restoration of physical activity and functional capacity are thus a major goal of antianginal therapy. Here, we show that ivabradine significantly improved the distribution of CCS class, with a majority of patients (67\%) rated as class I at 4 months. The proportion of patients with activity-limiting angina ( $\geq$ class II) decreased from 73 to $33 \%$. Accordingly, this reduction in angina severity was accompanied by an improvement in scores of quality of life, which include assessment of mobility, usual activities, and self-care. This improvement was noted in all analyzed subpopulations, including patients with previous MI or PCI, diabetes, and the elderly. These results indicate that ivabradine effectively improves health status and physical activities in a broad range of angina patients seen in clinical practice.

The incidence of adverse drug reactions, especially bradycardia, was considerably lower in our pooled analysis than in large, randomized outcome trials with ivabradine [36-38]. This might be explained by several factors. The baseline (up to $11 \mathrm{bpm}$ ) and achieved heart rate (up to $9 \mathrm{bpm}$ ) was higher, and mean daily doses of ivabradine were lower (up to $5 \mathrm{mg}$ /day) in our cohort, which may have contributed to prevent bradycardia and other dose-dependent adverse reactions in general. Furthermore, the use of concomitant cardiovascular medication like beta blockers, ACE inhibitors, statins, and aspirin was considerably less pronounced in our study population, which might have also reduced susceptibility to adverse drug reactions, e.g. by avoidance of potential drug interactions.

In line with its indication, our results confirm the antianginal effectiveness of ivabradine in patients with an elevated heart rate $(\geq 70 \mathrm{bpm})$, with a reduction in angina attacks and use of short-acting nitrates by $87 \%$. Moreover, the drug retained a similar effectiveness when used in combination with a beta-blocker. When focusing on patients with an elevated heart rate despite the use of the most commonly prescribed beta-blocker, metoprolol [4], the number of angina attacks and use of short-acting nitrates were significantly reduced with the addition of ivabradine treatment (by 88 and $87 \%$, respectively). Despite the widespread use of beta-blockers, elevated heart rate persists in many patients and is associated with more frequent angina and ischemia [39]. Thus, the addition of 
ivabradine may be considered in all eligible patients with a heart rate $\geq 70 \mathrm{bpm}$, including those already treated by a beta-blocker, to further reduce the heart rate and improve symptoms of angina.

The main limitation of the present analysis is the lack of control group, which might have biased the results by overestimating the treatment effect. Definitions of comorbidities were not prespecified and were left to the judgment of the physicians. Another limitation may be the short treatment duration of 4 months, which on the other hand was sufficient to evaluate symptomatic effects of ivabradine in several controlled trials [10, 12-14]. Antianginal efficacy and safety have also been shown for a longer period of 12 months in a randomized study [11]. Finally, observational trials can lead to an underestimation of adverse events, as they were spontaneously reported and not specifically sought.

\section{Conclusion}

We have shown, based on this short-term data, that ivabradine is an effective and well-tolerated antianginal treatment in a broad range of patients seen in real clinical practice, including diabetic patients as well as patients with previous MI and/or PCI. Antianginal effectiveness was also maintained in the elderly and in patients with concomitant beta-blockers. In addition, ivabradine improved the quality of life in all analyzed subpopulations.

\section{Acknowledgments}

The authors would like to thank all participating investigators for their contributions to the studies analyzed in this publication. We thank Julie Salzmann, PhD, who provided medical writing assistance on behalf of Servier, France.

\section{Conflict of Interest}

K. Werdan has been engaged in ivabradine clinical trials fully or partly supported by Servier, has received honoraria for lectures from Servier, was a member of the German ivabradine advisory board of Servier, and received research grants for experimental and clinical ivabradine research from Servier. T. Meinertz was a member of the German ivabradine advisory board of Servier. S. Perings, R. Köster, M. Kelm, and U. Müller-Werdan report no conflicts of interest. G. Stöckl is an employee of Servier (Medical Affairs). This pooled analysis was funded by Servier.

\section{References}

1 Panza JA, Diodati JG, Callahan TS, Epstein SE, Quyyumi AA: Role of increases in heart rate in determining the occurrence and frequency of myocardial ischemia during daily life in patients with stable coronary artery disease. J Am Coll Cardiol 1992;20:1092-1098.

2 Andrews TC, Fenton T, Toyosaki N, Glasser SP, Young PM, MacCallum G, Gibson RS, Shook TL, Stone PH: Subsets of ambulatory myocardial ischemia based on heart rate activity. Circadian distribution and response to anti-ischemic medication. The Angina and Silent Ischemia Study Group (ASIS). Circulation 1993;88:92-100.

3 Riccioni G: Ivabradine: the hope for a good treatment of ischemic heart disease. Curr Med Chem 2013;20:1817-1823.

4 Montalescot G, Sechtem U, Achenbach S, Andreotti F, Arden C, Budaj A, et al: 2013 ESC guidelines on the management of stable coronary artery disease: the Task Force on the management of stable coronary artery disease of the European Society of Cardiology. Eur Heart J 2013;34:2949-3003.

5 Thollon C, Vilaine JP: $I_{\mathrm{f}}$ inhibition in cardiovascular diseases. Adv Pharmacol 2010;59: 53-92.
6 Dillinger JG, Maher V, Vitale C, Henry P, Logeart D, Manzo SS, Allee G, Levy BI: Impact of ivabradine on central aortic blood pressure and myocardial perfusion in patients with stable coronary artery disease. Hypertension 2015;66:1138-1144.

7 Tagliamonte E, Cirillo T, Rigo F, Astarita C, Coppola A, Romano C, Capuano N: Ivabradine and bisoprolol on Doppler-derived coronary flow velocity reserve in patients with stable coronary artery disease: beyond the heart rate. Adv Ther 2015;32:757-767.

8 Mangiacapra F, Colaiori E, Ricottini E, Balducci F, Creta A, Demartini G, Di Sciascio G: P6291: heart rate reduction by ivabradine for improvement of endothelial function in patients with coronary artery disease: the randomized open-label RIVENDEL study. Eur Heart J 2015;36(suppl 1):1105.

9 Gloekler S, Traupe T, Stoller M, Schild D, Steck H, Khattab A, Vogel R, Seiler C: The effect of heart rate reduction by ivabradine on collateral function in patients with chronic stable coronary artery disease. Heart 2014; 100:160-166.
10 Borer JS, Fox K, Jaillon P, Lerebours G: Antianginal and antiischemic effects of ivabradine, an $I_{\mathrm{f}}$ inhibitor, in stable angina: a randomized, double-blind, multicentered, placebo-controlled trial. Circulation 2003;107:817-823.

11 Lopez-Bescos L, Filipova S, Martos R: Longterm safety and efficacy of ivabradine in patients with chronic stable angina. Cardiology 2007;108:387-396.

12 Ruzyllo W, Tendera M, Ford I, Fox KM: Antianginal efficacy and safety of ivabradine compared with amlodipine in patients with stable effort angina pectoris: a 3-month randomised, double-blind, multicentre, noninferiority trial. Drugs 2007;67:393-405.

13 Tardif JC, Ford I, Tendera M, Bourassa MG, Fox K: Efficacy of ivabradine, a new selective $I_{\mathrm{f}}$ inhibitor, compared with atenolol in patients with chronic stable angina. Eur Heart J 2005;26:2529-2536.

14 Tardif JC, Ponikowski P, Kahan T: Efficacy of the $I_{\mathrm{f}}$ current inhibitor ivabradine in patients with chronic stable angina receiving betablocker therapy: a 4 month, randomized, placebo-controlled trial. Eur Heart J 2009;30: 540-548. 
15 European Medicines Agency: Procoralan: EPAR - Product Information. http://www. ema.europa.eu/ema/ (accessed November 17, 2015).

16 Tendera M, Borer J, Tardif J: Efficacy of $I_{\mathrm{f}}$ inhibition with ivabradine in different subpopulations with stable angina pectoris. Cardiology 2009;114:116-125.

17 Kennedy-Martin T, Curtis S, Faries D, Robinson S, Johnston J: A literature review on the representativeness of randomized controlled trial samples and implications for the external validity of trial results. Trials 2015;16:495.

18 Werdan K, Ebelt H, Nuding S, Höpfner F, Hack G, Müller-Werdan U: Ivabradine in combination with beta-blocker improves symptoms and quality of life in patients with stable angina pectoris: results from the $\mathrm{AD}$ DITIONS study. Clin Res Cardiol 2012;101: 365-373.

19 Köster R, Kaehler J, Meinertz T: Treatment of stable angina pectoris by ivabradine in every day practice: the REDUCTION study. Am Heart J 2009;158:e51-e57.

20 Perings S, Stöckl G: Ivabradine treatment in chronic stable angina patients with or without concomitant beta-blocker therapy: effectiveness, treatment response and tolerability in clinical practice. Clin Res Cardiol 2014; 103(suppl 2):102.

21 Werdan K, Ebelt H, Nuding S, Höpfner F, Stöckl G, Müller-Werdan U: Ivabradine in combination with beta-blockers in patients with chronic stable angina after percutaneous coronary intervention. Adv Ther 2015;32: 120-137.

22 Werdan K, Ebelt H, Nuding S, Höpfner F, Stöckl G, Müller-Werdan U: Ivabradine in combination with metoprolol improves symptoms and quality of life in patients with stable angina pectoris: a post hoc analysis from the ADDITIONS trial. Cardiology 2016; 133:83-90.
23 Van Spall HG, Toren A, Kiss A, Fowler RA: Eligibility criteria of randomized controlled trials published in high-impact general medical journals: a systematic sampling review. JAMA 2007;297:1233-1240.

24 Montamat SC, Cusack BJ, Vestal RE: Management of drug therapy in the elderly. N Engl J Med 1989;321:303-309.

25 Deedwania PC: Management of patients with stable angina and type 2 diabetes. Rev Cardiovasc Med 2015;16:105-113.

26 Dagenais GR, Lu J, Faxon DP, Bogaty P, Adler D, Fuentes F, Escobedo J, Krishnaswami A, Slater J, Frye RL: Prognostic impact of the presence and absence of angina on mortality and cardiovascular outcomes in patients with type 2 diabetes and stable coronary artery disease: results from the BARI 2D (Bypass Angioplasty Revascularization Investigation 2 Diabetes) trial. J Am Coll Cardiol 2013;61: 702-711.

27 Borer JS, Tardif JC: Efficacy of ivabradine, a selective $I_{\mathrm{f}}$ inhibitor, in patients with chronic stable angina pectoris and diabetes mellitus. Am J Cardiol 2010;105:29-35.

28 Pop-Busui R: Cardiac autonomic neuropathy in diabetes: a clinical perspective. Diabetes Care 2010;33:434-441.

29 Anselmino M, Ohrvik J, Rydén L: Resting heart rate in patients with stable coronary artery disease and diabetes: a report from the Euro Heart Survey on Diabetes and the Heart. Eur Heart J 2010;31:3040-3045.

30 Maddox TM, Reid KJ, Spertus JA, Mittleman M, Krumholz HM, Parashar S, Ho PM, Rumsfeld JS: Angina at 1 year after myocardial infarction: prevalence and associated findings. Arch Intern Med 2008;168:1310-1316.

31 Brorsson B, Bernstein SJ, Brook RH, Werkö L: Quality of life of patients with chronic stable angina before and four years after coronary revascularisation compared with a normal population. Heart 2002;87:140-145.
32 Maranta F, Tondi L, Agricola E, Margonato A, Rimoldi O, Camici PG: Ivabradine reduces myocardial stunning in patients with exercise-inducible ischaemia. Basic Res Cardiol 2015; 110:55.

33 Gerbaud E, Montaudon M, Chasseriaud W, Gilbert S, Cochet H, Pucheu Y, Horovitz A, Bonnet J, Douard H, Coste P: Effect of ivabradine on left ventricular remodelling after reperfused myocardial infarction: a pilot study. Arch Cardiovasc Dis 2014;107:33-41.

34 Westermann D, Savvatis K, Wollenberg U, Limberg R, Maier LS, Bauersachs J: Prevalence of obstructive coronary artery disease in ambulatory patients with stable angina pectoris. J Clin Exp Cardiol 2015;6:387.

35 Izzo P, Macchi A, De Gennaro L, Gaglione A, Di Biase M, Brunetti ND: Recurrent angina after coronary angioplasty: mechanisms, diagnostic and therapeutic options. Eur Heart J Acute Cardiovasc Care 2012;1:158-169.

36 Fox K, Ford I, Steg PG, Tardif JC, Tendera M, Ferrari R: Ivabradine in stable coronary artery disease without clinical heart failure. $\mathrm{N}$ Engl J Med 2014;371:1091-1099.

37 Fox K, Ford I, Steg PG, Tendera M, Ferrari R Ivabradine for patients with stable coronary artery disease and left-ventricular systolic dysfunction (BEAUTIFUL): a randomised, double-blind, placebo-controlled trial. Lancet 2008;372:807-816.

38 Swedberg K, Komajda M, Böhm M, Borer JS, Ford I, Dubost-Brama A, Lerebours G, Tavazzi L: Ivabradine and outcomes in chronic heart failure (SHIFT): a randomised placebo-controlled study. Lancet 2010;376:875885

39 Steg PG, Ferrari R, Ford I, Greenlaw N, Tardif JC, Tendera M, Abergel H, Fox KM: Heart rate and use of beta-blockers in stable outpatients with coronary artery disease. PLoS One 2012;7:e36284. 